\title{
Science and fun in a Magic Show of Light from optical demonstrations on an overhead projector for elementary school students
}

Joe Lones, Nadezhda Maltseva, Kurt Peterson

Joe J. Lones, Nadezhda K. Maltseva, Kurt N. Peterson, "Science and fun in a Magic Show of Light from optical demonstrations on an overhead projector for elementary school students," Proc. SPIE 9665, Tenth International Topical Meeting on Education and Training in Optics and Photonics, 96651H (3 June 2007); doi: 10.1117/12.2207700

SPIE Event: Tenth International Topical Meeting on Education and Training in Optics and Photonics, 2007, Ottawa, Ontario, Canada 


\title{
Science and Fun in a "Magic Show of Light" from Optical Demonstrations on an Overhead Projector for elementary school students.
}

\author{
Joe J. Lones ${ }^{\mathrm{a}}$, Nadezhda K. Maltseva ${ }^{\mathrm{b}}$, Kurt N. Peterson ${ }^{\mathrm{c}}$ \\ ${ }^{a}$ Adroit Engineering, P.O. Box 6245 San Diego, CA 92166-0245 \\ ${ }^{b}$ SPb SU ITMO, 49, Kronverkskiy Av., St. Petersburg, Russia 197101 \\ ${ }^{c}$ Clarenceville School District Board of Education, Livonia, Michigan
}

\begin{abstract}
We seek methods of stimulating young school children to develop an interest in science and engineering through a natural curiosity for the reaction of light. Science learning now begins fully at middle school. Reading skills develop with activity at home and progress through the elementary school curriculum, and in a like manner, a curious interest in science also should begin at that stage of life. Within the ranks of educators, knowledge of optical science needs to be presented to elementary school students in an entertaining manner. One such program used by the authors is Doug Goodman's Optics Demonstrations With the Overhead Projector, co-published by and available from OSA (Optical Society of America) and SPIE-The International Society of Optical Engineering. These demonstrations have found their way into middle and high schools; however, as a special approach, the authors have presented selected Goodman demonstrations as a "Magic Show of Light" to elementary schools. Both students and faculty have found the show most entertaining! If optical knowledge is utilized to stimulate science learning in the coming generation at elementary school level, there's a good chance we can sow some fertile seeds of advancement for all future segments of the workforce. Students can enjoy what they are doing while building a foundation for contributing gainfully to society in any profession. We need to explore expanding exposure of the "Magic Show of Light" to elementary schools.
\end{abstract}

OCIS codes: (000.2060) Education

\section{OPTICS EDUCATION NOW AND FOR THE FUTURE}

\subsection{Getting "Out of the Box"}

Successful education produces individuals who possess a large foundation of conceptual knowledge coupled with a wide range of problem-solving and communication skills. While memorizing is important, largely in organizing concepts, practicing effective reasoning develops habits of logical analysis and focused searching for solutions. In addition, the pursuit of scientific principles requires clear and accurate communication, often a nontrivial goal. The word from higher academia and the workplace is that significant portions of today's high-school graduates are missing technological, problem solving, and communication skills. ${ }^{1}$

Root causes for the current educational dilemma come from many directions. One such cause could be the emphasis on rapid action. Then too, there's "the box." Yep, that ubiquitous computer and its "box" counterpart, TV, have invaded our lives, and the world, with excessive attention to on-screen images... Haven't we all heard about "out of the box"?

"For a whole generation of kids, direct experiences in the backyard, in the tool shed, in the fields and woods, have been replaced by indirect learning, through machines," states Frank Wilson, medical director of the performing-arts health program at the University of California School of Medicine (San Francisco. CA). "These young people are smart, they grew up with computers, they were supposed to be superior--but now we know that something's missing."

So what does a member of the optics--or education--community do to solve such problems, or at least work to correct them? Answering deals with the when and the how.

First, though, it's important to recognize that math and science education produces extended skills, assuming students have good reading skills (another essential subject we don't have room to discuss here). Those extended skills force the student to engage the mind "out of the box"--not exactly what a "cyberspace-educated" middle- and high-school student readily embraces.

Tenth International Topical Meeting on Education and Training in Optics and Photonics, edited by Marc Nantel, Proc. of SPIE Vol. 9665, 96651 - @ 2007 SPIE, OSA, IEEE, ICO doi: $10.1117 / 12.2207700$ 


\section{2. "THE WHEN" - Early in Life}

We really need improvement in science and math education, which most often begins in middle school. Good reading skills are developed with activities at home and in the elementary school curriculum, and in a like manner, interest in math and science learning also needs to begin at that stage of life. If a young person has not been stimulated to have an interest in the logical analysis and focused-solution approach before reaching middle school, it is going to be hard--most likely impossible--to get going. There are always exceptions in any grouping; however, let's consider what can be done for the elementary school student body in general to improve awareness and interest in math and science.

Learning skills proceed most effectively when learning is both fun and informative. Since math and science are based on a foundation of logic, it follows that their basic knowledge is most useful in life--even if one does not choose to pursue a career in science. Just consider the implications of a generation of students implanted with the notion that science is fun!

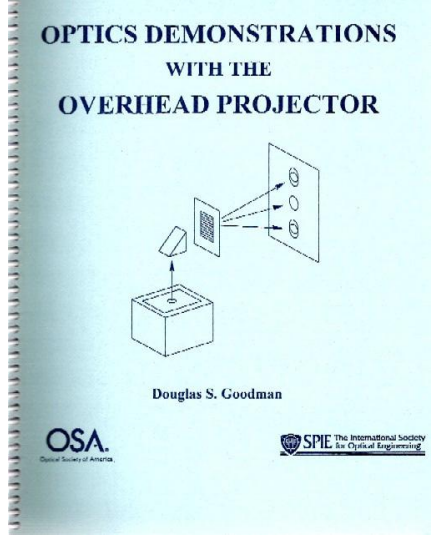

Fig. 1. Douglas S. Goodman "Optics Demonstrations With the Overhead Projector"

\section{3. "THE HOW" - An Educational Presentation to show Science is REALLY FUN}

Within the ranks of SPIE, there is a wealth of knowledge easily accessible to expose science to elementary school students in an entertaining manner. One such program is Douglas Goodman's Optics Demonstrations With the Overhead Projector ${ }^{3}$, co-published by and available from OSA and SPIE, Fig. 1. The demonstrations have already found their way into middle and high schools; however, a special approach is required for elementary school demonstrations. Performing a select set of the Goodman demonstrations as a Magic Show of Light is extremely well received by elementary school students. Demonstrations need to be chosen for their simplicity and entertainment. In so doing the demos can really hold the limited attention span of elementary school students, who get quite excited at the action. A sampling of the Goodman demonstrations that work well for elementary school students include Lamp Reimaged, which uses a simple lens to show what the projector lamp looks like; Handedness or Parity, which involves rotating an image around the room with a mirror; and Rainbow, which shows how light through a water drop creates a rainbow.

A major impediment to convincing elementary school teaching staff they can present the Goodman demonstrations is an understandable lack of knowledge in the science of optics. Yes, it wouldn't be appropriate to "lecture" on a subject of which one is not knowledgeable, for questions from the audience would become problematic. So what we must do is shift the activity from being perceived as a "lecture" to an opportunity for "entertainment".

We are currently experiencing movement to promote bringing science into the elementary school curriculum. A lesson plan stimulating optical scientific curiosity will create just such an event, which hopefully can someday become part of a National Science Education Standard for Teaching at elementary school. To that end what follows is an introductory Magic Show Script. Presenters need only follow the script with freedom to "ad lib" according to reactions of the elementary school "audience". It is imperative to keep in mind the presentations are to be purely entertainment.... NOT A SCIENCE LECTURE! ${ }^{4}$

It really works! (See the Epilogue.) Try it with the Introductory Demonstration Script that follows and watch for more details of a full production script "coming soon to a classroom like yours". 


\section{AN INTRODUCTORY DEMONSTRATION FOR THE MAGIC SHOW OF LIGHT - WHERE MAKING SCIENCE FUN IS IN FOCUS!}

...Today I am bring you a Magic Show of Light, but I will break the Magicians' rules and give some hints about how the magic tricks are done.

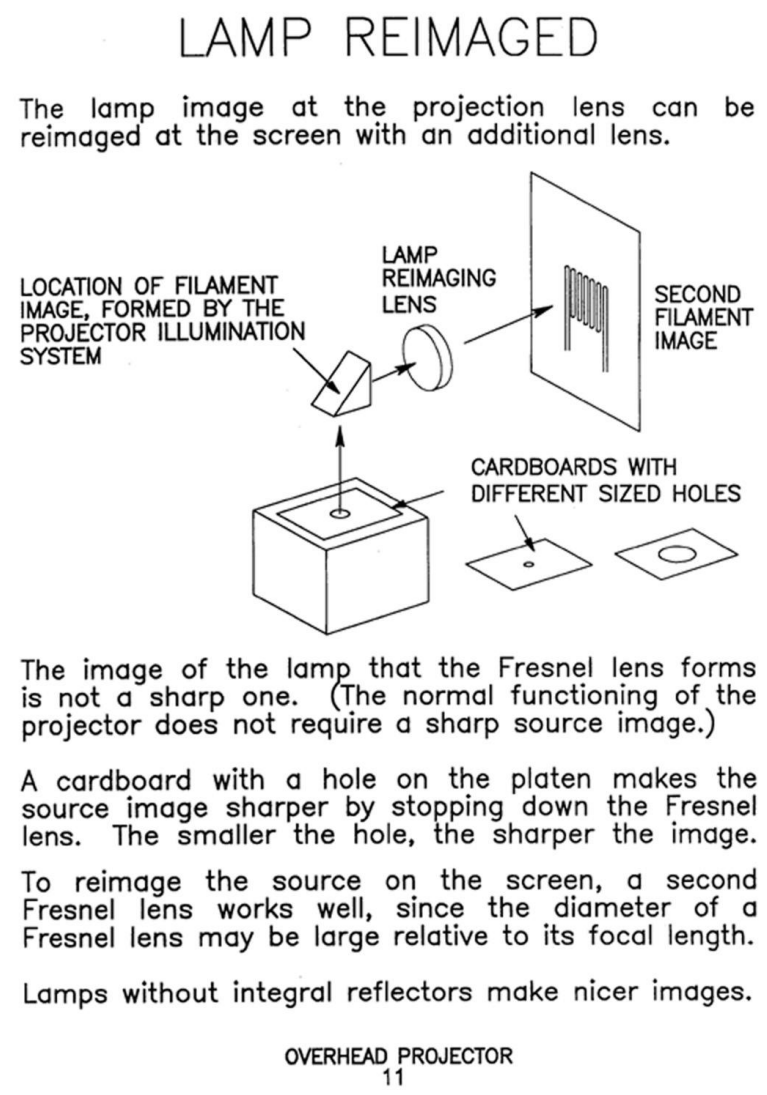

Fig. 2. Lamp Reimaged Demonstration from Doug Goodman "Optics Demonstrations with the Overhead Projector"

...Deep inside the box at the bottom of the projector is a very bright light bulb.

...I have in my hands a "Magic Lens" with which we will look into the box and find the light bulb.

...There it is! (See Note below.)

...Look, you can see the bright wires that are in the middle of the light bulb.

...The wires are glowing very hot which makes the light for all the fun we will have today.

...We can see the wires because this "Magic Lens" reaches inside the box and puts a picture of the wires on the screen for us to see.

Note to Presenter:

1. It is important to use the cardboard with a hole in the center.

2. To focus the lamp image - hold the lens by the edges and place it in the center of the beam on the side of the projector head facing the screen as shown in Fig. 2. Move the lens slowly toward the screen along the axis of the beam from touching the projector head to a point where the image appears in focus on the screen. (The results are quite spectacular!) 


\section{A LIST OF GOODMAN DEMONSTRATIONS ADAPTABLE TO A “MAGIC SHOW OF LIGHT”}

Technical description pages from Optics Demonstrations with the Overhead Projector listed in suggested order of presentation for the Magic Show of Light are presented in the following table.

Table The Suggested Order of Presentations

\begin{tabular}{|c|c|c|c|}
\hline No. & TITLE & SECTION & PAGE \\
\hline 1 & Lamp Reimaged & Overhead Projector & 11 \\
\hline 2 & Handedness or Parity & Overhead Projector & 7 \\
\hline 3 & Object and Image Rotation & Imaging - Basic Properties & 10 \\
\hline 4 & Image Revolution Without Rotation & Monochromatic Ray Optics - Prism & 15 \\
\hline 5 & Lens Sharing & Imaging - Additional Optics & 15 \\
\hline 6 & Rotating Transmission Scanner & $\begin{array}{l}\text { Monochromatic Ray Optics - Plane Parallel } \\
\text { Plate }\end{array}$ & 8 \\
\hline 7 & Total Internal Reflection & Monochromatic Ray Optics & 19 \\
\hline 8 & Imaging Through Turbulent Media & Imaging - Degradation & 44 \\
\hline 9 & Wave Patterns & Monochromatic Ray Optics - Miscellaneous & 18 \\
\hline 10 & $\begin{array}{l}\text { Complimentary of Transmitted and Reflected } \\
\text { Light }\end{array}$ & Interference Colors & 5 \\
\hline 11 & Absorption Spectroscope & Spectroscope & 3 \\
\hline 12 & Rainbow & Polychromatic Ray Optics & 8 \\
\hline 13 & $\begin{array}{l}\text { Varying Syrup Distance Through which Light } \\
\text { Passes }\end{array}$ & Polarization - Optical Activity & 35 \\
\hline $13 \mathrm{a}$ & Polarizer Material Sources & Polarization & 9 \\
\hline $13 b$ & Some Practical Considerations & Polarization & 6 \\
\hline 14 & Patterns with Different Periods & Moiré & 7 \\
\hline
\end{tabular}

\section{PLANTING SEEDS FOR THE FUTURE OF ELEMENTARY SCHOOL EDUCATION}

If optical science is utilized to stimulate the coming generation at elementary school level, there's a good chance we can sow some fertile seeds of advancement for all segments of the workforce. The goal is that the students will not only enjoy what they will be doing but also will be contributing gainfully to society in the future.

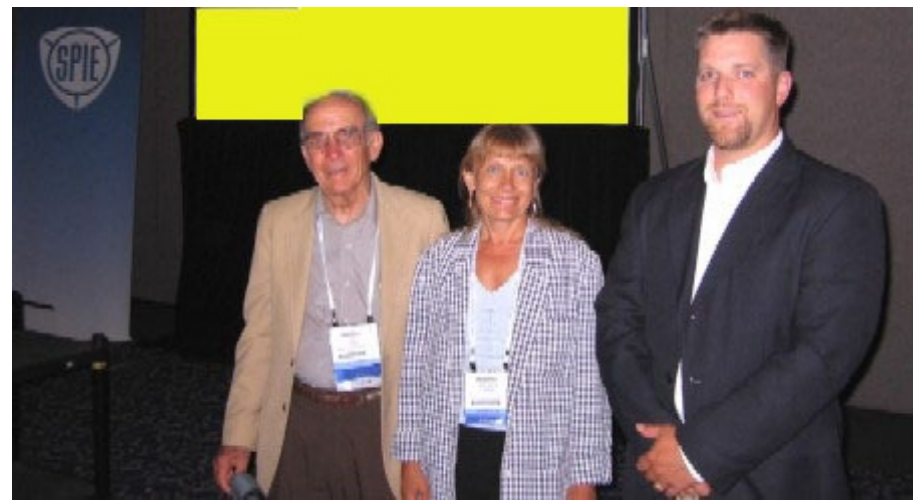

Fig.3. Joe Lones, Nadya Maltseva, and Kurt Peterson - Advocating Science for Elementary School 


\title{
5. EPILOGUE - ON BIRTH OF THE MAGIC SHOW OF LIGHT
}

\author{
SPIE Members Reach out to Improve Science Education ${ }^{5}$
}

If you were to ask a group of $5^{\text {th }}$ graders what they wanted to be when they grew up, what percentage of them would you expect to say, 'I want to be an optical engineer!' ZERO, perhaps? Right you are! And why is that? The answer may seem obvious, but its importance shouldn't be over looked: THEY DON'T KNOW WHAT AN OPTICAL ENGINEER IS. The result of the same experiment on a group of high school seniors would probably not be much different. At a time when few students are electing to pursue careers in science, and demand for trained optical scientists and engineers is on the rise, it is important to let people know what we do and why we love it.

SPIE member Doug Goodman helps entertain a group of $5^{\text {th }}$ graders from Brookline, Massachusetts each year when they visit Polaroid's Optical Engineering Department. The students play with optical toys, tour the facility from the machine shop to the vacuum deposition chamber, delight in optical demonstrations performed by Doug with an overhead projector, and then ask questions. How many of these students would you expect to say they wanted to be optical engineers? After a show like that, I wouldn't be surprised if half of them spent at least the next week dreaming about playing with light all day, just like that cool scientist Dr. Goodman.

Joe Lones, SPIE Fellow member and President/CEO of Adroit Engineering, Inc., has had the opportunity to take some of Doug's demonstrations on the road. He sent me the following description of his first performance in front of an elementary school audience, with which I will leave you.

It becomes both a challenge and fun to stimulate young student minds using science demonstrations with a little imagination. Optics probably is one of the most portable of the sciences that can grab the attention of a younger generation - provided it is presented in a context that is both informative and entertaining. When professionals share their world of satisfaction in scientific endeavor it can launch a new generation of problem solvers over unlimited fields often unrelated to the original exposure. What follows is but one success story not at all uncommon when students find science and engineering can be fun.

The San Diego Section of the Optical Society of America has embarked on an endeavor with the cooperation of SPIE to assemble a demonstration kit to perform the classical Optics Demonstrations on an Overhead Projector ingeniously created by Doug Goodman of Polaroid. These demonstrations have proven to be quite popular in middle school and high school classrooms.

Giving absolutely no thought to the idea that Goodman's Demonstrations were determined above the heads of the elementary school crowd, this father responded to his daughter's request to appear in her teaching classroom on a day that the entire school would be having a Science Discovery Day. After all, in the eyes of daughters, daddies are supposed to know everything, so this project was launched with confidence on all sides. Dad had decided that he'd have no trouble finding words appropriate to a group of third graders. However, approaching the big day, daughter informed Dad that... since this would be a day of science for all the school, the principal had requested a change of venue for the visiting science demonstration. Dad would be performing before an assembly of the whole school!

By due process Dad's confidence was thoroughly rattled when, on the way to the school, it suddenly became a grim reality that the audience would consist of young minds in the stages of development from kindergarten to the sixth grade! As setup was completed and the room filled with students, faculty, and even the entire cafeteria staff, Dad was still wondering what he's going to do with this crowd? Anyhow, one very important item loomed in his favor... No one out there had the foggiest idea what was about to happen.

This being a last minute change in the schedule, no announcement had been made except that a third grade teacher would introduce her Dad.

With elementary school students assemblies lasted usually thirty minutes, only a few of the optical demonstrations were selected. Dad was getting down to the wire for starting this debacle, and then an amazing thing happened. Pulling from early childhood memory of just such an assembly and remembering the delight when a magician regularly came to be featured, dad announced to a gleeful reception that a "Magic Show of Light" would begin. It was then announced that as a special treat for everyone, the magicians' rule would be broken by explaining how all the tricks would be done. Let me tell you, that place went up in pandemonium then quickly hushed at energizing of the projector for a screen of many colors starting the show.

Lenses, prisms, mirrors, filters, and slits went into the projector's optical path to applause at every event on the screen, the walls, and the ceiling ... followed again by immediate hush as the phenomena was concisely explained to 
the sixth graders in the back of the room. In the end there was a spectacularly messy Karo syrup polarization demonstration followed by a five-minute overtime encore of moiré fringe patterns eliciting laughs around the room.

All done, dad packed his stuff in the car, departed, and received a startling phone call from daughter that evening: Dad was now in big time trouble! He has been invited to bring the "Magic Show of Light" back every year! That day was the first time the school staff could recall experiencing an assembly without one student misbehaving.

Just maybe, someday, there's gonn'a be a few scientists and engineers emerge from those eager young minds... And that's just plain fun to contemplate!!! - Thanks to Doug Goodman!!!

\section{Acknowledgments}

Generous participation of members of the Optical Society of San Diego, a Chapter of the Optical Society of America, for assembling original props used in presenting Douglas Goodman Demonstrations

\section{References}

1. Gollub, Jerry P. \& Spital, Robin, Advanced Physics in High Schools, Physics Today, May 2002, pp. 48-53

2. Louv, Richard, The Future's Edge, Silicon Faith: Third in a series, San Diego Union-Tribune, 10 February 2002, p. A9

3. Douglas S. Goodman, Optical Demonstrations With The Overhead Projector, OSA, Washington DC, 2000

4. $\quad$ Lones, Joe J., Planting the Seed, SPIE's OE magazine, July 2002, p. 55

5. Excerpted from Outreach column in Optical Engineering Reports published by SPIE, November, 19, 1999 